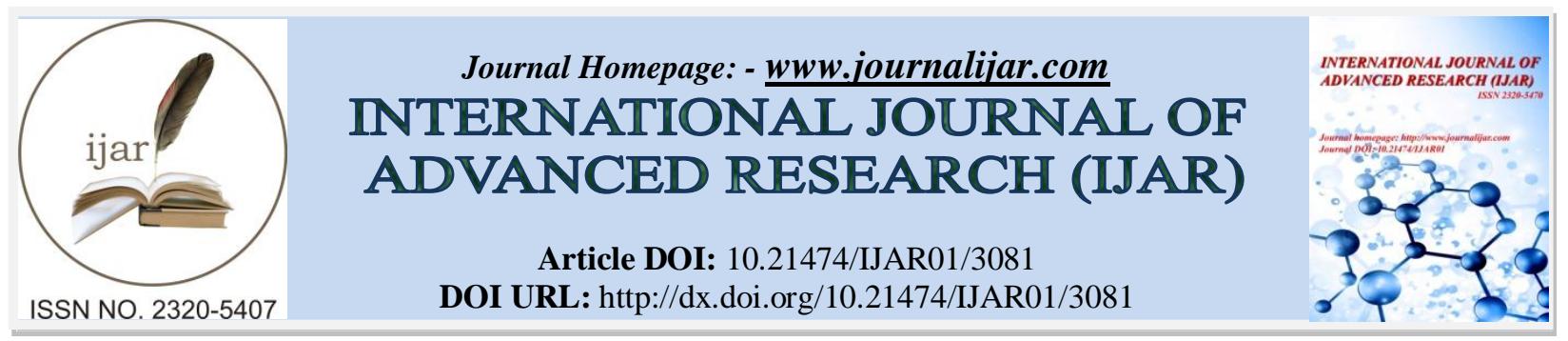

RESEARCH ARTICLE

\title{
PRODUCTION OF NUTRITIOUS JAM BY USING AN UNDERUTILIZED FRUIT AVVERHOA CARAMBOLA (STAR FRUIT).
}

\author{
Trivedi Disha ${ }^{1}$, Wadia Ashok ${ }^{2}$, Nina Dias ${ }^{1}$ and Kataria Roonal ${ }^{2 *}$. \\ 1. Department of Foods, Nutrition and Dietetics, Nirmala Niketan College of Home Science, Churchgate \\ 2. Department of Microbiology, Jai Hind College, Churchgate
}

\section{Manuscript Info} .........................

\section{Manuscript History}

Received: 03 November 2016

Final Accepted: 28 December 2016

Published: January 2017

Key words:-

Carambola, jam making, preservation, shelf-life, nutritive value

\section{Abstract}

Making of jams is the common methods of preserving fruit, the main factor being high concentration of sugar that helps in preservation. Carambola is a sub-tropical fruit found in Indonesia, Malaysia, etc. In India the fruit is available in the months of September through October and January through February. The main health benefits of carambola are anti-inflammatory, analgesic, hypoglycemic, antimicrobial, hepatoprotective and anti-ulcer activity. Product development was carried out using carambola fruit. The jam was developed as a complete natural product with no added preservatives. Organoleptic properties of the product were assessed by sensory evaluation and the jam was found to be acceptable. Shelf-life study of the jam was carried out by microbial analysis and it was found that there was a decrease in the no. of microbial contaminants. Nutritive value of the product was also analyzed; the results obtained were Protein $0.88 \%$, Fat $0.19 \%$, Carbohydrates $44.89 \%$, Energy $185 \mathrm{kcal}$, Dietary fiber $1.68 \%$, Magnesium $156 \mathrm{mg}$ and Vitamin C $5 \mathrm{mg}$ per 100 gms.

Copy Right, IJAR, 2016,. All rights reserved.

\section{Introduction:-}

Food is something that is consumed not only for its varied taste but also for its nutritional importance. Food usually provides the humans with ample nutrients such as proteins, carbohydrates, fats, vitamins, minerals \& energy. The sources of food are plants and animals, plant sources being the fruits \& vegetables. As most of the fruits are seasonal and perishable in nature, its processing is a must. To ensure the supply of wholesome, safe, nutritious and acceptable food to the consumers, there should be processing of fruits into various products that could be preserved for a long time and which adds value to the product. Processing of fruits not only serves as a purpose of its preservation but also several other purposes such as diversification of the economy, reduction of imports and meeting export demands, stimulate agricultural production by obtaining marketable products, generate employment, reduce fruit \& vegetable losses, develop new value added products which are also available during off-seasons (Bakshi \& Joshi; 2013).

Avverhoa Carambola or commonly called as star fruit is a native fruit to Tropical Asia, Indonesia, Malaysia and other exotic regions such as Australia, Brazil , Cambodia etc. India's Carambola season is throughout the year; but it flourishes during two times i.e. September through October \& January through February. It prefers warm climate and can be grown in India on the hills up to 1,200 m. In spite of its high availability, it is an underutilized fruit in the 
Indian market. The fruit have a high water content and is a rich source of dietary fiber, Vitamin $\mathrm{C}$, antioxidant phyto-nutrients such as polyphenols and flavonoids, B-complex vitamins such as folates, riboflavin, and pyridoxine. It also carry small amount of minerals and electrolytes like potassium, phosphorus, and zinc and iron (Ferrera, 2009).

Carambola has a potent antioxidant and antimicrobial activity. It boosts the immune system to fight against toxic free radicals and other common infections. The insoluble dietary fiber helps in digestion and also in lowering blood cholesterol. According to the studies carried out by Dasgupta et.al in 2013 on Avverhoa carambola, the plant is proved to possess medicinal properties such as anti-inflammatory, analgesic, hypoglycemic, antimicrobial, hepatoprotective and anti-ulcer activity and therefore the plant $\&$ its fruit can be used as a potent medicine.

Carambola fruits have a very high nutritive value but a sour taste which makes it unpopular. The availability of the fruit throughout the year makes it a good choice to be used for development of new products with an appealing taste. Attempts have been made to develop commercial products from carambola such as essence, juice and wine (Nagy et.al, 1990; Napahde et.al, 2010). The present study aims to develop jam using carambola and to study its quality, stability and nutritional properties.

\section{Materials and Methods:- Product development:-}

Avverhoa carambola was purchased from the local market. Experimental trial jams were prepared using the fruit pulp, different concentrations of granulated sugar and commercial pectin. Plate test was performed to determine the setting point of jam as described by Khanna and Gupta, 1993.

\section{Sensory evaluation:-}

The trial samples were subjected to sensory evaluation by 10 semi-trained panelists to determine the acceptability of the samples. The jam was evaluated on a 5 point hedonic scale where 1 is the lowest point and 5 is the highest point for that particular characteristic. The characteristics on which the jam was evaluated were appearance, color, taste, texture, mouth-feel, aftertaste and overall acceptability (Lawless and Haymenn, 1999).

\section{Nutritional analysis:-}

Nutritional analysis of the jam was carried out at Anazeal Analyticals \& Research Pvt. Ltd. Labs. The overall content of proteins, fats, carbohydrates, energy, dietary fiber, calcium, phosphorus, potassium, magnesium, Vitamin $\mathrm{C}$ provided per $100 \mathrm{gm}$ of jam sample was determined (Pathak and Chakraborthy, 2006).

\section{Shelf life and Stability studies:-}

A microbial challenge study was carried out by growth inhibition method on jam samples to evaluate the stability and safety of a product with respect to food borne pathogens and spoilage-causing microorganisms. The samples were challenged by inoculating them with common spoilage organisms and food-borne pathogens i.e. Escherichia coli, Staphylococcus aureus, Bacillus cereus and Saccharomyces cerevisiae individually and incubated at $28^{\circ} \mathrm{C}$ for 20 days (US FDA, 2009)

At different time intervals aliquots were obtained from these samples, adequately diluted and plated on selective media and incubated for growth of the contaminants. Nutrient agar, MacConkey's agar, Baird parker's agar and Sabourad's agar were used for enumeration of Bacillus cereus, Escherichia coli, Staphylococcus aureus and Saccharomyces cerevisiae, respectively.

Viable counts were determined at zero time, after 5 days, 10 days, 15 days and 20 days of storage of the samples at room temperature. Uninoculated controls were also maintained and total bacterial and mould counts were determined on Nutrient agar and Sabouraud's agar.

\section{Results and Discussions:- Product Development:-}

The quality of jam is determined by the proportions of sugar and pectin added to the fruit pulp. Ideally jams contain $50-65 \%$ of sugars which gives the product a bright colour and natural stability. To optimize the sugar and pectin content in the final product, trial jams were developed using different variations as tabulated below (Table 1). 
Table 1:- Optimization of sugar and pectin content

\begin{tabular}{|c|c|c|}
\hline Trials & Sugar Concentration \% & Pectin Concentration \% \\
\hline Trial 1 & 60 & 0 \\
\hline Trial 2 & 40 & 5 \\
\hline Trial 3 & 60 & 3 \\
\hline Trial 4 & 60 & 2 \\
\hline Trial 5 & 60 & 1 \\
\hline
\end{tabular}

The production parameters, mainly the degree to which the pulp is homogenized and the time and temperature used for processing also affect drastically the quality of the jam produced, and this is well reflected in the sensory assessment of jams.

The product that was standardized was a pectin-free product as designed in trial 2. It constituted of pulp-125 gms and sugar- $75 \mathrm{gms}$ and was processed for 25 minutes. At lesser concentrations the characteristic gel consistency is lost whereas higher sugar content cause crystallization in the jam. Jams will less sugar content were also susceptible to spoilage due to microbial fermentation and may need chemical preservatives (Sidappa and Lal; 1998).

The work carried out by Patil et al in 2010 has shown that the pectin content of mature fruits of carambola is very high $(5 \%)$. The jam formed using only pulp and sugar had a bright colour and smooth consistency which had set well as demonstrated by plate test. There was no need to add commercial pectin as the frit itself was pectin-rich.

\section{Sensory Evaluation:-}

The sensory evaluation for the variations of the product showed that the jam with no pectin added was given the highest scores for all the parameters by the panelist. This was due to carambola having inherent pectin and therefore no commercial pectin was needed for a product with good consistency. Fig 1 gives the comparison of the mean scores obtained of the parameter studied for sensory evaluation for jams prepared with and without added commercial pectin.

Siddiqui et al in 2015 has used sapodilla for jam preparation. The source of pectin for this was the fruit peel. Sensory evaluation was carried out for the prepared jam and the consistency of the jam was approved. Commercial pectin was not required as the fruit peel was shown to possess gelling properties because of high pectin content. Fruit jams prepared without adding commercial pectin were found to be of acceptable quality if the fruit is rich in pectin.

Fig.1:- Comparison of acceptability for jam with and without added commercial pectin

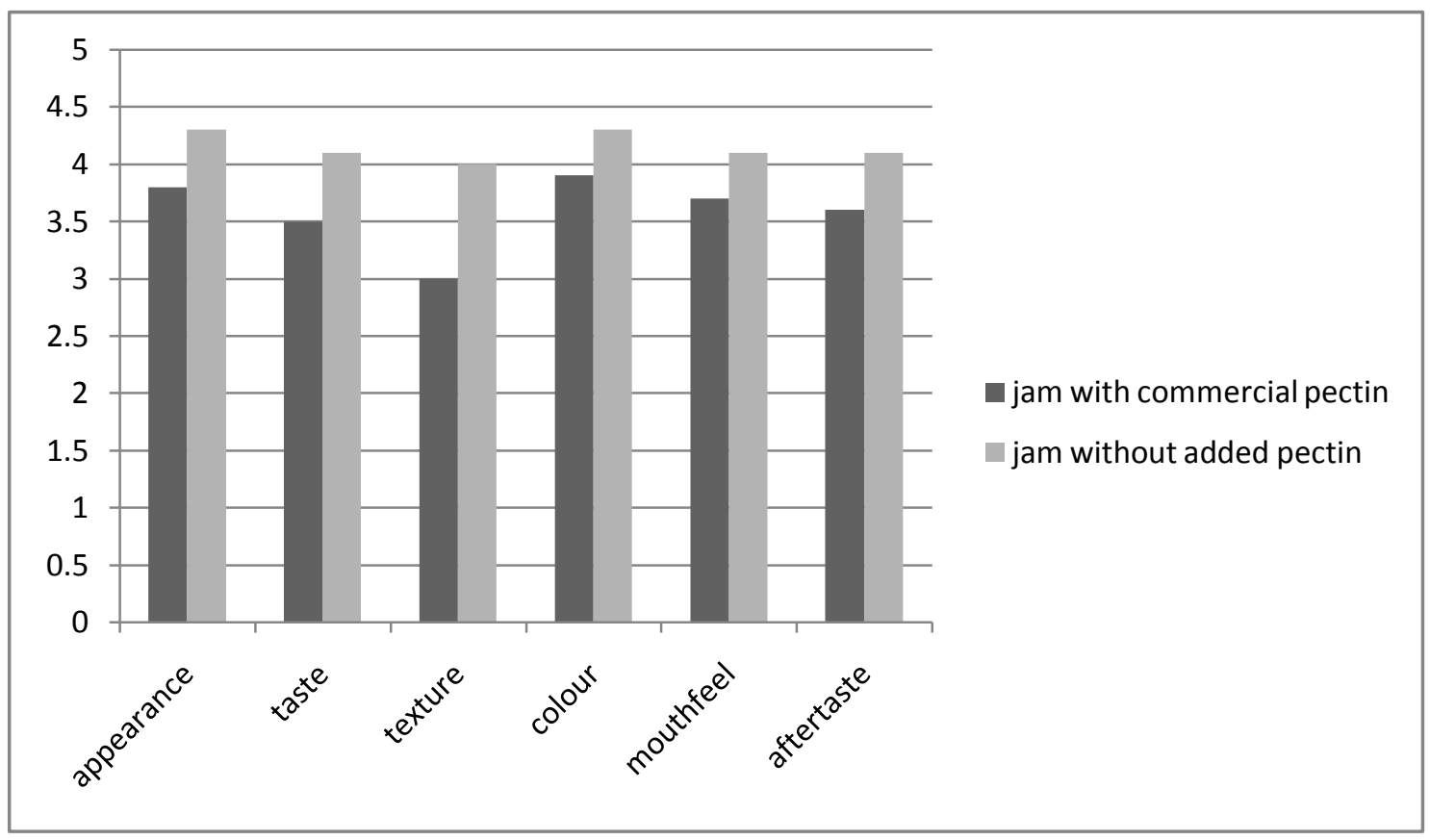




\section{Nutritional analysis:-}

Table 2 gives the nutritive value of the jam as determined for $100 \mathrm{gm}$. According to these results, it can be stated that the product contains certain minerals, Vitamin $\mathrm{C}$ and is an abundant source of energy.

Table 2:- Nutritive value/100 gm

\begin{tabular}{|l|l|}
\hline Nutrient & Nutrient value/100gm \\
\hline Protein & $0.88 \%$ \\
\hline Fat & $0.19 \%$ \\
\hline Carbohydrates & $44.89 \%$ \\
\hline Energy & $185 \mathrm{kcal}$ \\
\hline Dietary fiber & $1.68 \%$ \\
\hline Calcium as $\mathrm{P}_{2} \mathrm{O}_{5}$ & 0 \\
\hline Phosphorus - as P & $0.08 \%$ \\
\hline Potassium & $0.18 \%$ \\
\hline Magnesium & $0.37 \%$ \\
\hline Vitamin C & $156 \mathrm{mg}$ \\
\hline
\end{tabular}

The pulp and seeds of quince fruit was used to prepare jam by Silva et al in 2004 and the antioxidant activity of the product as well as the raw pulp and seeds were studied. Their results showed that the product showed a very good activity which can be correlated to its Vitamin $\mathrm{C}$ content. A slight reduction in the activity was reported for the processed jams as compared to the raw pulp and seed.

\section{Shelf life and Stability testing:-}

Shelf-life study was carried out to check the keeping quality of the carambola jam. The primary reasons for the deterioration of the product are the micro-organisms, leading to change in the physical attributes and organoleptic properties of the product. The product standardized is a $100 \%$ natural jam with no added preservatives, with the ingredients only being carambola and sugar. Therefore, the only preserving factor in the jam is sugar. Caramola jam is an acid food, rich in carbohydrates, and is therefore vulnerable to the growth of microbial agents such as yeasts and molds. Therefore, shelf-life study of the standardized product was carried out by growth inhibition test for 20 days at an interval of 5 days with storage at room temperature. Before inoculating the challenge organisms, baseline level of microorganisms present in the product were determined as control. .

Control sample, without any inoculation of the challenge organisms showed product to be safe and of good quality microbiologically. The results obtained for challenged samples are mentioned in Table 3

Table 3:- Results of shelf life study.

\begin{tabular}{|c|c|c|c|c|c|c|}
\hline \multirow[b]{2}{*}{$\begin{array}{c}\text { No. of } \\
\text { days }\end{array}$} & \multicolumn{4}{|c|}{ Inoculated Jam } & \multicolumn{2}{|c|}{$\begin{array}{c}\text { Uninoculated Jam } \\
\text { (Control) }\end{array}$} \\
\hline & $\begin{array}{l}\text { B.cereus } \\
\text { (cfu/gm) }\end{array}$ & $\begin{array}{l}\text { S.aureus } \\
\text { (cfu/gm) }\end{array}$ & $\begin{array}{c}\text { E.coli } \\
(\mathrm{cfu} / \mathrm{gm})\end{array}$ & $\begin{array}{c}\text { S.cerevisiae } \\
(\mathrm{cfu} / \mathrm{gm})\end{array}$ & $\begin{array}{c}\text { Yeast } \\
\text { (cfu/gm) }\end{array}$ & $\begin{array}{l}\text { Bacteria } \\
\text { (cfu/gm) }\end{array}$ \\
\hline 0 & $2 * 10^{3}$ & $2.5^{*} 10^{3}$ & $3 * 10^{3}$ & $1 * 10^{3}$ & 20 & 12 \\
\hline 5 & 257 & 35 & 60 & 40 & 20 & 7 \\
\hline 10 & 213 & 16 & 13 & 20 & 15 & 5 \\
\hline 15 & 191 & 0 & 0 & 3 & 2 & 0 \\
\hline 20 & 163 & 0 & 0 & 0 & 0 & 0 \\
\hline
\end{tabular}

According to results obtained for the 20-day shelf life study, there is a decrease in the number of bacteria, yeasts and molds contaminants in the jam. The common spoilage causing micro-organisms which were used for shelf-life study were Bacillus cereus and Saccharomyces cerevisiae. The bottles in which micro-organisms were inoculated also showed a decreased gradation in the microbial population. This indicates that the sugar concentration in the jam i.e. $60 \%$ was enough for the inhibition of spoilage causing micro-organisms. At this concentration the microbial contaminants are not able to survive in the product and hence the product would not be spoiled quickly.

The studies carried out by Viberg et al in 1997 on blackcurrant jam prepared without chemical additives had shown that the jam can remain stable for a period of 13 months at low temperature. The sugar content of the jam was $23 \%$. Microbial analyses carried ot at regular should no growth of bacteria, yeasts and molds, sporeformers and pathogens. The nutritional value and the minerals and vitamin content were found to be within the acceptable value. The colour, viscocity and appearance of the jam were stable. 


\section{Conclusion:-}

An acceptable product i.e. jam with the use of Carambola, an uncommon and underutilised fruit was formulated. This jam was developed as a $100 \%$ natural product with no added preservatives. The product was found to be acceptable based on the sensory evaluation using Hedonic-scale. It is also nutritious and beneficial for health serving as a good source of anti-oxidants, minerals and dietary fiber. It was found to have a stable product with a defined shelf-life. The sugar concentration added was enough to prevent the food contaminants like B.cereus and S.cerevisiae from growing and causing the deterioration of the product. Thus, a nutritious Carambola jam which was sensorily accepted with a good keeping quality was developed. Additionally, different products of carambola can be formulated like carambola juice, confectionary (candy) or marmalade.

\section{References:-}

1. Abdullah A, Cheng TC. 2001. Optimization of reduced calorie tropical mixed fruits jam. Food Qual Pref. 12:63-68.

2. Bakshi AK, Joshi VK, Vaidya D, Sharma S. 2013. Processing \& Preservation of fruits of Himalayan region; Food processing \& preservation- Part I. New Delhi: Jagmander book agency, pp 288-292

3. Dasgupta P, Chakraborty P, Bala NN. 2013. Averrhoa Carambola: An Updated Review; International Journal of Pharma Research \& Review. 2: 54-63

4. Ferrara L. 2009. Functional properties of Averrhoa carambola L. Ingredienti Alimentari. 8: 16-19

5. Khanna K, Gupta S. 1993. Preservation of fruits \& vegetables at home; the art \& science of Cooking-A student's manual. 2nd Edition. Elite Publishing House Pvt Ltd; pp 280-282

6. Lawless HT, Heymann H. 1999. Introduction \& overview; Sensory evaluation of food-principles \& practice. New York: Kluwer academic/ Plenum publishers, pp 1-24

7. Nagy S, Barros S, Carter R. 1990. Production and Characterization of Carambola essence. Proceedings Florida State Horticultural Science. 103: 27-279

8. Napahde S, Durve A, Bharti D, Chandra N. 2010. Wine Production from Carambola (Averrhoa carambola) Juice using Sachharomyces cerevisieae. Asian journal of experimental biological sciences. 20-23

9. Pathak PK, Chakraborthy I. 2006. Studies on Physico-chemical characters of some potential underutilized tropical fruits. Proceedings of the national symposium on production, utilization \& export of underutilized fruits. 4:.271-274

10. Patil A, Patil D, Pathak A, Chandra N. 2010. Physical and Chemical Characteristics of Carambola (Averrhoa carambola L.) fruit at three stages of maturity. International Journal of Applied Biology and Pharmaceutical Technology. 1: 624-629.

11. Sidappa GS, Lal G. 1998. Jams, Jellies \& Marmalades; Preservation of fruits and vegetables. Indian council of agricultural research. 157-170.

12. Siddiqui NH, Azhar I, Tarar OA, Masood A, Mahmood ZA. 2015. Influence of pectin concentrations on physico-chemical and sensory qualities of jams. World Journal of Pharmacy and Pharmaceutical Sciences. 4: 68-77

13. Silva BM, Andrade PB, Valentão P, Ferreres F, Seabra RM, Ferreira MA. 2004. Quince Fruit and Jam Antioxidant Activities. J. Agric. Food Chem. 52: 4705-12

14. US FDA. 2009. Chapter 6. Microbiological Challenge Testing. Available from: http://www.fda.gov/Food/FoodScienceResearch/SafePracticesforFoodProcesses/ucm094154.htm

15. Viberg U, Ekström G, Fredlund K, Öste RE, Sjöholm I. 1997. A Study of Some Important Vitamins and Antioxidants in a Blackcurrant Jam with Low Sugar Content and Without Additives. International Journal of Food Sciences and Nutrition. 48: 57-66 